\title{
BERLO Janet C. et Ruth B. PHILLIPS, Amérique du Nord. Arts premiers
}

\section{Marie Mauzé}

\section{OpenEdition \\ Journals}

Édition électronique

URL : https://journals.openedition.org/jsa/10811

DOI : 10.4000/jsa. 10811

ISSN : 1957-7842

\section{Éditeur}

Société des américanistes

\section{Édition imprimée}

Date de publication : 23 juillet 2009

Pagination : 229-232

ISSN : 0037-9174

\section{Référence électronique}

Marie Mauzé, « BERLo Janet C. et Ruth B. PHILLIPS, Amérique du Nord. Arts premiers », Journal de la Société des américanistes [En ligne], 95-1 | 2009, mis en ligne le 10 juillet 2009, consulté le 03 septembre 2022. URL : http://journals.openedition.org/jsa/10811 ; DOI : https://doi.org/10.4000/jsa. 10811

Ce document a été généré automatiquement le 3 septembre 2022

Tous droits réservés 


\title{
BERLO Janet C. et Ruth B. PHILLIPS, Amérique du Nord. Arts premiers
}

\author{
Marie Mauzé
}

\section{RÉFÉRENCE}

BERLO Janet C. et Ruth B. PHILLIPS, Amérique du Nord. Arts premiers, traduit de l'anglais par Nelcya Delanoë et Joëlle Rostkowski, Albin Michel, coll. « Terre indienne », Paris, 2006, $263 \mathrm{p}$.

1 Avec Amérique du Nord. Arts premiers ${ }^{1}$ signé de deux historiennes de l'art, Janet Berlo et Ruth Phillips, nous avons là un ouvrage qui fait partie d'une nouvelle génération de travaux sur les arts nord-amérindiens, à l'instar du livre de David W. Penney, North American Indian Art, publié en $2004^{2}$. Connues pour l'excellence de leurs recherches, Berlo et Phillips proposent une étude exhaustive sur l'ensemble des arts visuels nordamérindiens considérés dans leur contexte culturel et historique. Dans les chapitres consacrés aux principales régions (Sud-Ouest, Est, Ouest, Nord, côte Nord-Ouest) - le découpage est sensiblement différent de celui généralement convenu pour les grandes aires culturelles -, elles traitent des dynamiques à l'œuvre dans les processus de création, les évolutions, les mutations, les emprunts qu'ont subis les arts au cours des millénaires à la suite des migrations, des déplacements, des déportations et de la sédentarisation des peuples amérindiens avec l'établissement des réserves. Chaque chapitre est construit selon le même canevas, ce qui engendre une grande cohérence dans la manière dont les matériaux et les informations sont abordés.

2 C'est dans le chapitre I que Berlo et Phillips posent clairement les objectifs de leur étude : faire découvrir la richesse des modes d'expression artistiques dans leur profondeur diachronique et leur diversité régionale. Elles rendent compte des principes fondamentaux qui sous-tendent la création artistique, des événements historiques ou des situations singulières qui signalent des changements ou des ruptures qui font partie inhérente de l'histoire de ces arts visuels. Se refusant à céder à une vision ethno-centriste 
en établissant une frontière entre préhistoire et histoire (la période historique commençant avec l'arrivée des Européens), elles montrent que les cultures autochtones ont toujours fait preuve d'une grande capacité d'adaptation à leur environnement et insistent sur le fait que les différents groupes qui ont peuplé l'Amérique du Nord ne vivaient pas en isolats, mais, au contraire, faisaient partie de vastes réseaux d'échanges culturels et commerciaux. Le parti pris des auteurs est d'accorder aussi une place à l'art contemporain et à la parole des artistes, tout en insistant sur la continuité des traditions. Déclin et renaissance artistiques sont envisagés comme faisant partie d'un même processus historique. Berlo et Phillips ne se contentent pas d'analyser les styles et leur évolution, elles expliquent également le cadre culturel dans lequel ces arts se sont développés et rendent compte de la diversité et de la spécificité des modes d'expression artistique (vêtements, décorations corporelles, objets rituels) pour chacune des régions (et sous-régions) traitées dans l'ouvrage. Sont ainsi mis en relation types d'organisation sociale, systèmes de croyance, techniques et formes d'expression. La question : «Qu'estce-que l'art amérindien?» conduit bien évidemment Berlo et Phillips à définir les critères d'évaluation des cultures locales et à s'interroger sur le problème, tant rebattu par les ethnologues, les historiens de l'art, les conservateurs et les galeristes, de l'authenticité - problème peu pertinent pour les Amérindiens. En effet, la fabrication d'objets à destination du marché a permis d'assurer aux autochtones un revenu lors de périodes sombres de leur histoire, mais aussi de maintenir une continuité dans la transmission de la tradition orale et des savoirs techniques ainsi que de stimuler la production artistique. Pour un autochtone, tout objet fabriqué par un autochtone, quelle que soit sa destination, est par définition authentique. Les arts visuels constituent, en effet, un lieu privilégié de l'affirmation de la mémoire collective et de la résistance aux coups de butoir portés à la culture et à la religion amérindienne par la politique coloniale et post-coloniale.

3 Dans ce chapitre méthodologique, est traitée la question du genre associé généralement à la double dichotomie sacré/profane, art/artisanat, étant entendu que l'art sacré ressortit au domaine masculin, tandis que les femmes sont vouées à fabriquer des objets de la vie quotidienne, donc profanes. S'appuyant sur des cas précis, les deux auteurs battent en brèche le discours convenu qui a mis en exergue l'art des hommes au détriment de celui des femmes; elles soulignent, par exemple, que dans la région des Grands Lacs, le tissage, activité féminine par excellence, est intimement lié à un savoir secret et à des pouvoirs surhumains; de même, dans de nombreuses cultures, la vannerie est associée à la détention par les femmes d'un savoir spirituel qui a à voir non pas seulement avec le répertoire des motifs qui décorent les objets, mais aussi avec la collecte des matériaux bruts et leur traitement. Au-delà de la complémentarité des rôles masculins et féminins, des transgressions étaient possibles dans certaines conditions. Aujourd'hui, le champ des activités artistiques est plus ouvert et en conséquence la notion de genre est moins pertinente, qu'il s'agisse de technique, de style ou encore de la nature des matériaux : c'est ainsi qu'on trouve des potiers chez les Pueblo ou des femmes sculpteurs sur la côte Nord-Ouest.

4 Avec le dernier chapitre consacré à l'art amérindien contemporain, Berlo et Phillips explorent les questions relatives à la catégorisation des modes d'expression artistique autochtone (artisanat ou beaux-arts), à celle des styles quand on sait que, dans certaines régions, les productions sont directement influencées par les styles traditionnels comme sur la côte Nord-Ouest et, dans d'autres, les artistes sont formés dans des écoles d'art réservées aux artistes autochtones, à l'instar du fameux Institute of American Indian Arts 
(IAIA) de Santa Fé, ce qui a contribué à redéfinir de manière radicale le statut de l'art amérindien contemporain à partir des années 1960. À l'époque dite "moderne " (1950-1980), où les artistes s'inspirent pourtant de thèmes de l'iconographie indienne ou de l'indianité en général, les productions artistiques indigènes sont restées enfermées dans la catégorie des arts dits primitifs et n'ont généralement pas réussi à être reconnues comme des œuvres à part entière, dignes de figurer dans les musées ou les galeries d'art. Avec les créations post-modernes (installations, vidéo, performances) qui se développent dans les années 1980, les artistes peuvent-ils se prévaloir de faire partie de la communauté artistique occidentale ? Poser la question, c'est déjà y répondre en partie : si certaines œuvres utilisant des formes d'expression contemporaine sont reconnues, d'autres demeurent dans la catégorie " art autchtone », notamment celles qui s'inspirent des traditions orales. Force est de constater que les critères occidentaux du jugement esthétique continuent à s'imposer dans l'appréciation des œuvres amérindiennes contemporaines.

5 L'ouvrage de Berlo et Phillips est, à juste titre, considéré comme un classique des études sur les arts visuels amérindiens, en raison de la richesse de son contenu, de la pertinence et de l'actualité des débats qu'il suscite. Rendons hommage à Joëlle Rostkowski qui a eu l'idée de proposer ce livre à la traduction chez Albin Michel et à Nelcya Delanoë qui l'a accompagnée dans cette tâche. La traduction française a été faite dans un style enlevé propre à séduire un public plus large que celui des étudiants ou des spécialistes auxquels était destinée son édition originale. Dans sa version française, le livre est amputé de l'index et d'un "bibliographic essay» de vingt pages qui accompagne chaque chapitre et sous-partie de chapitre. Même si les références citées dans la version originale étaient en totalité publiées en anglais, ce choix éditorial est contestable car il édulcore la portée intellectuelle de l'ouvrage initial et prive l'amateur éclairé d'un outil de documentation remarquable. Le choix du titre est, lui aussi, discutable : l'éditeur a succombé à la mode du moment - d'ailleurs déjà dépassée -, celle de faire figurer l'expression "arts premiers », expression provinciale s'il en est, car exclusivement française.

\section{NOTES}

1. Publié originellement sous le titre Native North American Art, Oxford University Press, Oxford, 1998.

2. Penney David W., North American Indian Art, Thames \& Hudson, Londres, 2004. 


\section{AUTEURS}

MARIE MAUZÉ

Laboratoire d'anthropologie sociale/CNRS, Paris 